\title{
El tiempo a través del tiempo ${ }^{1}$
}

\author{
Timer over time
}

Eduardo Vicente Navarro

Facultad de Filosofía y Ciencias de la Educación. Universidad de Valencia

vinae@alumni.uv.es

\begin{abstract}
Resumen
Abstract

El presente ensayo pretende ser una introducción The present essay is designed to be a general general al problema filosófico del tiempo desde sus introduction to the philosophical problem of time from its muy diferentes formas y posibilidades de ser abordado. very different forms and ways of approaching. In this En este sentido, el artículo recorre el problema desde sense, the article covers the problem from different diferentes puntos de vista y da breve cuenta de la perspectives and gives a brief account of the plurality pluralidad y diversidad de los tiempos que se and diversity of the time found in the different encuentran en las diferentes definiciones filosóficas, en philosophical definitions, in the different layers of los diferentes estratos del saber, en las diferentes knowledge, in different periods and cultures and also in épocas y culturas, y también en los diferentes the different instruments used to measure time itself. instrumentos que miden el propio tiempo.
\end{abstract}

Palabras clave: Temporalidad

Keywords: Temporality

\section{Introducción a la perplejidad del tiempo}

¿Qué es el tiempo? ¿La perplejidad de Heráclito ante el río²? ¿La elegante definición de Platón: el tiempo como "imagen móvil de la eternidad inmóvil" (Tim., 37 D)? ¿O la enunciación impecable de Aristóteles: "el número (orden) del movimiento según el antes y el después" (Phys., IV, II, 220a)? ¿O

${ }^{1}$ El presente ensayo constituye la parte introductoria del Trabajo de Investigación en el Departamento de Metafísica y Teoría del Conocimiento del programa de doctorado "Razón, Lenguaje e Historia" de la Facultad de Filosofía y Ciencias de la Educación de la Universidad de Valencia.

2 "Yo diría que siempre sentimos esa antigua perplejidad, esa que sintió mortalmente Heráclito en aquél ejemplo al que vuelvo siempre: nadie baja dos veces el mismo río. ¿Por qué nadie baja dos veces el mismo río? En primer término, porque las aguas del río fluyen. En segundo término -esto es algo que ya nos toca metafísicamente, que nos da como un principio de horror sagrado-, porque nosotros mismos somos también un río, nosotros también somos fluctuantes. El problema del tiempo es ése. Es el problema de lo fugitivo: el tiempo pasa" (Borges, 1979: 85). 
se trata más bien del si me lo preguntas ya no lo sé de San Agustín? ¿Qué es el tiempo? ¿El Detente. ¡Eres tan hermoso...! de Johann W.Goethe? ¿O es una forma de intuición a priori de la sensibilidad, como dice Immanuel Kant? ¿O se trata más bien del Espíritu de Georg Wilhelm Friedrich Hegel desplegándose? ¿Qué es el tiempo? ¿La doctrina del eterno retorno de lo idéntico que Friedrich Nietzsche vislumbró en Sils-María, "a 6000 pies sobre el nivel del mar y mucho más alto aún sobre todas las cosas humanas"? ¿O somos nosotros mismos el tiempo, como asegura Martin Heidegger ${ }^{3} \ldots$ ?

A lo largo de la historia del pensamiento, las definiciones filosóficas se han sucedido de forma prolífica. Con el pasar de los siglos, la esfera del saber se ha ido erosionando hasta precipitarse y dar lugar a la sedimentación de estratos de tiempo específicos de cada ciencia. En el decurso de la historia, los ciudadanos de las diferentes épocas y culturas, han expresado una singular sensibilidad para con el tiempo. El tiempo mismo ha variado a través de los propios instrumentos de medición del tiempo y de las tecnologías sociales. Las siluetas del tiempo han variado ellas mismas a través del tiempo. Ahora bien, hay algo que al parecer permanece en todo este frenético transcurrir, a saber, el problema mismo del tiempo como sutil perplejidad y como dimensión fundamental del existir humano que resulta imprescindible a la hora de orientarnos y ordenar el devenir del mundo.

El presente ensayo tan sólo pretende siquiera apuntar estos problemas y esta diversidad a la hora de abordar la cuestión del tiempo. Y es que, no es empresa liviana el deslindar qué sea el tiempo. No le faltaba razón a Bergson al ver en la cuestión del tiempo acaso el problema nuclear de la metafísica. Estamos, pues, ante una de las problemáticas filosóficas por excelencia, y, quizá habría también que añadir a lo dicho, que nos encontramos ante un problema cuya naturaleza está revestida de una cierta aura de misterio. Al parecer, la perplejidad del tiempo no sólo es fruto de la diversidad de definiciones al respecto, no sólo se debe a que el tiempo sea un concepto que varía él mismo a través del propio tiempo, a través de sí mismo, y ni siquiera se debe en exclusiva a que el tiempo sea una dimensión de la existencia humana fundamental; al parecer, existe también en la naturaleza del tiempo un algo enigmático, un conocimiento último que en última instancia se nos escapa, o al menos esa es la sensación que nos trasmite la tradición del pensamiento.

Pensemos, por ejemplo, en Aristóteles - primer pensador que nos ofrece un tratado sistemático sobre el tiempo-, precisamente comienza su estudio reconociendo la dificultad y oscuridad del problema, y exponiendo como punto de partida ineludible las aporías que circulan a su alrededor. La principal razón por la cual Aristóteles pone en duda la existencia del tiempo, es por estar compuesto de "noseres". Y es que, el pasado ya no es, el futuro todavía no es y el presente es y no es a cada punto. Siglos más tarde, San Agustín recogerá los ecos de las aporías aristotélicas y dirá: "pasado y futuro, ¿cómo pueden existir si el pasado ya no es y el futuro no existe todavía? En cuanto al presente... si el presente para ser tiempo es preciso que deje de ser presente y se convierta en pasado, ¿cómo decimos que el presente existe si su razón de ser estriba en dejar de ser? No podemos, pues, decir con verdad que existe el tiempo sino en cuanto tiende a no ser" (San Agustín, 1997: 327). Con ello

\footnotetext{
3 “¿Quién es el tiempo? Más en concreto: ¿Somos nosotros mismos el tiempo? Y con mayor precisión todavía: ¿Soy yo mi tiempo? Esta formulación es la que más se acerca a él. Y si comprendo debidamente la pregunta, con ello todo adquiere un tono de seriedad. Por tanto, ese tipo de pregunta es la forma adecuada de acceso al tiempo y de comportamiento con él, con el tiempo como el que es en cada caso el mío. Desde un enfoque así planteado, el ser-ahí sería el blanco del preguntar" (Heidegger, 1995: 12).
} 
se expresa esa forma de ser elusiva e intermitente que caracteriza al tiempo misterioso: que palpita entre la existencia y la inexistencia, entre el conocimiento y el desconocimiento. Parece que es, pero se compone de no-seres; parece que lo sé, pero cuando me lo preguntan ya no lo sé.

Desde luego, existen otras paradojas y perplejidades que afectan al pensamiento que versa sobre el tiempo, como por ejemplo la de Zenón de Elea -tan brillantemente dilucidadas por Henri Bergson (1957). En cualquier caso, no es mi intención detenerme durante más tiempo en este punto. Pero lo que sí quisiera advertir es que, tal vez, en ocasiones sucede que esperamos una solución al enigma del tiempo, un tipo de respuesta, que no encaja con el carácter del tiempo.

Al parecer, como dice Lewis Carroll (1865: 71): "El Tiempo no soporta que lo marquen ni que lo clasifiquen". El tiempo no se deja congelar en la parálisis de los conceptos. Quizá el problema reside en que buscamos algo así como la verdad del tiempo. Más, ¿es el tiempo susceptible de ser verdadero o falso? No recuerdo ahora quién dijo que "el océano no es correcto ni incorrecto", pero parece seguro que no existe una respuesta y una verdad única y límpida acerca de qué sea eso del tiempo. Sin embargo, el alma de San Agustín arde tras la respuesta límpida. "Estoy ardiendo en deseos de solucionar este intrincadísimo problema -suplica San Agustín a Dios-. Te pido por Cristo que pueda penetrar en él" (San Agustin, 1997: 334). Podemos imaginar ahora a San Agustín, tras su muerte, con el alma ardiendo sobre la palma de su mano, finalmente preguntándole a Dios: ¡Oh Dios, tú que todo lo sabes, dime acaso qué sea aquello a lo que llamamos tiempo, porque mi alma no ha dejado de arder! Y entonces Dios le diría... ¿Qué le diría? Esta es la clase de respuesta, de verdad, que tendemos a buscar. Pero la verdad es que no sabemos que le diría Dios a San Agustín. Tal vez le diría que la respuesta palpita y arde precisamente en la palma de su propia mano... Pero esta misma respuesta no le sería igualmente satisfactoria a un Aristóteles, a un Kant, a un Nietzsche o a un Bergson o a un Heidegger.

\section{De los estratos del tiempo}

No deja de ser sorprendente que algo en principio tan evanescente y paradójico como el tiempo, salpique y empape profundamente todos los estratos del pensamiento y del quehacer humano. Por más que la esfera del saber se ha especializado, en todos sus fragmentos, en todos esos estratos que son como las capas de una cebolla, el tiempo ha dejado su dimensión de influencia. De hecho, parece existir en las disciplinas del saber, algo así como la pasión por el tiempo. Desde la geología se enorgullecen del descubrimiento del "tiempo profundo", desde la biología se habla de la importancia de los llamados "relojes biológicos", desde la física se habla del tiempo como de la "cuarta dimensión"... Se habla, pues, de un tiempo propiamente físico, de un tiempo biológico, de un tiempo geológico, pero también, de un tiempo histórico, de un tiempo sociológico, de un tiempo psicológico, de un tiempo cosmológico, de un tiempo filosófico, de un tiempo teológico, etcétera. Se trata, en efecto, del problema -si es que es un problema- de la diversidad de los estratos del tiempo; y al parecer, desde cada una de estas perspectivas, desde cada uno de estos estratos, tienen algo peculiar que decir y es posible aprender algo acerca del tiempo.

Ahora bien, cada una de las diferentes disciplinas parte de unos presupuestos diferentes, y, debido a ello, esa diversidad de puntos de partida, provoca grandes choques en la arena del debate interdisciplinar. Así, por ejemplo, no será lo mismo abordar el problema del tiempo desde una perspectiva teológica que desde una perspectiva filosófica. En efecto, si tomamos como punto de 
partida a Dios y a la eternidad, para luego descender hasta los hombres y su temporalidad concreta y mundana, entonces, de alguna forma la indagación acerca del tiempo ya estará previamente diseñada, pues, seguirá un esquema, una dirección y un propósito bien enmarcados. Como dijo Heiddeger al comienzo de la conferencia que pronunció en 1924 ante la Sociedad Teológica de Marburgo: "si Dios fuera la eternidad, entonces la manera de considerar el tiempo inicialmente propuesta habría de mantenerse en un estado de perplejidad mientras no se conozca a Dios... Si nuestro acceso a Dios pasa por la fe y si el entrar en el tema de la eternidad no es otra cosa que esa fe, en tal caso la filosofía jamás tendrá acceso a la eternidad y, por consiguiente, en el plano metodológico nunca podrá tomarla como una posible perspectiva para discutir la cuestión del tiempo. La filosofía nunca podrá disipar esta perplejidad... El filósofo no cree" (Heidegger, 1995: 23-25).

Pero estas discrepancias, evidentemente, no sólo ocurren entre la teología y la filosofía, sino prácticamente entre todas y cada una de las disciplinas para con todas las demás. Así, por ejemplo, la profundidad del tiempo geológico no tendrá nada que ver con la levedad del tiempo cotidiano del transeúnte del día a día. Y esto es así porque, entre otras cosas, la efímera existencia de una vida humana es tan sólo un suspiro a escala geológica. En efecto, el tiempo que podemos concebir -dice Thomas Browne (2005)- se remonta solamente a cinco días antes de nuestra existencia, mientras que, como dice Stephen Jay Gould (1987: 20-21), "el tiempo profundo es tan difícil de asimilar, tan lejano a nuestra experiencia ordinaria, que se configura como un obstáculo para nuestro entendimiento... es algo tan extraño que sólo podemos comprenderlo metafóricamente".

Otro ejemplo de la disparidad existente entre los distintos modos de entender el tiempo, lo encontramos en el tiempo del científico en oposición al tiempo del poeta. Así, mientras el físico trabaja con un tiempo cuantitativo, operativo y lleno de precisión, por su parte, el poeta juega con un tiempo cualitativo, creativo, metafórico, subjetivo. El tiempo supuestamente objetivo de los físicos, como nos ha mostrado Bergson (1957), descuartiza la duración: la diseca, la secciona, la espacializa y la deforma, la objetiviza en vistas a fines pragmático-operacionales. O dicho con palabras de Bachelard (1932: 19): "Los físicos... en sus abstracciones, hacen de ella [de la duración] un tiempo uniforme y sin vida, sin término ni discontinuidad. Entregan entonces ese tiempo enteramente deshumanizado a los matemáticos. Al penetrar en las probetas de lo abstracto, el tiempo se reduce a una simple variable algebraica, la variable por excelencia, en adelante más apropiada al análisis de lo posible que al examen de lo real". En cambio, casi en el contrapunto de este tiempo físico segmentado, encadenado, objetivado, etcétera, se situaría el tiempo poético que, como indica el propio autor, es un tiempo vertical y metafísico, un tiempo que nace de la profundidad del instante y que se apila en una riqueza que no es cuantificable. "El poeta destruye la continuidad simple del tiempo encadenado para construir un instante complejo, para unir sobre ese instante numerosas simultaneidades". Se trata "de un tiempo que no sigue la medida, de un tiempo que llamaremos vertical para distinguirlo del tiempo común que huye horizontalmente con el agua del río, con el viento que pasa" (Bachelard, 1932: 115).

Como vemos, el tiempo se dice de muchas maneras -según autor, disciplina, época y cultura. Más ejemplos como estos podrían sumarse sin demasiada dificultad, podríamos ahora contrastar el tiempo teológico con el tiempo biológico, o el tiempo histórico con el tiempo psicológico, etc. Pero con todo, no habríamos reflejado suficientemente la variedad y rica disparidad nacida de los diferentes estratos del tiempo.

Sin embargo, toda esta pluralidad de tiempos, toda esta variedad, y toda esta pasión, quizá tienen en mi opinión- una cosa en común, a saber, que todos ellos son ficciones humanas útiles lanzadas 
desde los diferentes vértices de la vida en aras de habitar una realidad que deviene movediza, es decir, ficciones pragmáticas que nos ayudan a orientarnos y dotar de sentido el devenir del mundo, de tal suerte que nuestras acciones e investigaciones cobran una mejor significación y precisión dentro de esta atmósfera temporal cultural. Desde este punto de vista, puede ensayarse el abandono de los esquemas subjetivistas y objetivistas a la hora de abordar el problema del tiempo, en aras de introducir la dimensión del aprendizaje social y cultural. Al respecto resulta sumamente interesante la sociología del tiempo de Norbert Elias (1989), para quien el tiempo no es un dato subjetivo kantiano ni mucho menos un dato objetivo newtoniano, sino que se trata de un dato social. El tiempo no es algo independiente que existe por su cuenta, ni es algo que venga fijado genéticamente, ni tampoco responde a una única invención de un individuo particular aislado. Para Elias (1989), el tiempo es un instrumento simbólico de orientación imposible de comprender sin tener en cuenta el acervo cultural que se trasmite y se aprende de generación en generación. $Y$ sólo dentro del marco de una teoría adecuada del saber y del conocer que tenga en cuenta el aprendizaje humano y los procesos sociales en su evolución de larga duración, podremos comprender el fenómeno del tiempo.

\section{De la diversidad de los tiempos}

Queremos ver ahora algunas perspectivas o puntos de vista desde donde la filosofía puede decir algo a propósito del tema que nos traemos entre manos. Pero como sabemos, hay muchos ángulos desde donde la filosofía puede contemplar el problema. $Y$ es que, el problema del tiempo, es un problema metafísico -porque va más allá de lo físico-, es un problema epistemológico -porque de hecho afecta a la forma en que nos representamos la realidad-, es un problema antropológico -porque acaso podría formar parte de la estructura humana y habrá que ver cómo varía de cultura en cultura y de época en época-, es un problema ético-estético -porque influye profundamente en las maneras de vivir, de pensar y de actuar-, etc. Nosotros no podemos más que dar algunas pinceladas. Lo que vamos hacer a continuación consiste, simplemente, en mostrar las diferentes maneras en que es posible abordar el problema del tiempo, todo y señalando algunas perspectivas y distinciones básicas desde donde mirarlo.

Sin duda, una de las perspectivas desde donde mirar al tiempo, acaso la más angustiosa, sería desde el punto de vista de la muerte. Y creo que la filosofía ha dicho algo al respecto. De hecho, muchos pensarán -sobre todo el profesionalmente viejo- que la muerte es la encarnación misma del tiempo, algo así como el límite del tiempo. Por eso Heidegger (1995) se dio cuenta de que el tiempo también tiene un horizonte, un límite natural -tanto nuestro futuro (nuestras ilusiones) como nuestro pasado (nuestra memoria) tienen la fecha de caducidad que impone el nacimiento y la muerte. Y con razón Platón llegó a decir que la filosofía es la meditación de la muerte. Fijémonos al respecto en la cantidad de sistemas filosóficos que se pueden leer atendiendo a la postura que han tomado para con la muerte. En efecto, el límite de nuestro tiempo, es la piedra de toque de muchos y muy diversos sistemas filosóficos. Pensemos por ejemplo en el pensamiento de Miguel Unamuno y Jorge Luís Borges. Unamuno (1913: 17-18) dice: "No quiero morirme, no; no quiero, ni quiero quererlo; quiero vivir siempre, siempre, siempre, y vivir yo, este pobre yo que me soy y me siento ser ahora y aquí, y por eso me tortura el problema de la duración de mi alma, de la mía propia" Borges, por su parte, parece situarse en el contrapunto: "Aquí ya no entiendo a Miguel de Unamuno; yo no quiero seguir siendo Jorge Luis Borges, yo quiero ser otra persona. Espero que mi muerte sea total, espero morir en cuerpo y alma" (Borges, 1979: 25, 41). Incluso hay autores, como Emile Cioran, que han llegado más allá en su hastío, y le echan la culpa no ya a la muerte, sino al nacimiento mismo: ¿o acaso no 
resultaría mejor y más sofisticado no haber nacido, es decir, permanecer en un estado de pura posibilidad?. "No corremos hacia la muerte; huimos de la catástrofe del nacimiento... Nos repugna, es verdad, considerar al nacimiento una calamidad: ¿acaso no nos han inculcado que se trata del supremo bien y que lo peor se sitúa al final, y no al principio, de nuestra carrera? Sin embargo, el mal, el verdadero mal, esta detrás, y no delante de nosotros" (Cioran, 1973: 10).

Unos quieren vivir para siempre, otros quieren morir absolutamente, mientras que otros preferirían no haber nacido. Al final, la reflexión acerca del sentido de la vida, cuando anda de por medio el problema del límite del tiempo que es la muerte, parece no tener demasiado sentido: "La vida es sólo una sombra caminante, un mal actor que, durante su tiempo, se agita y se pavonea en la escena, y luego no se le oye más. Es un cuento contado por un idiota, lleno de ruido y furia, y que no significa nada" (Shakespeare, 1623: 133). ${ }^{4}$

Démonos cuenta, por lo demás, cómo casi insensiblemente hemos ido cambiando de registro, de ángulo desde donde abordar el tema del tiempo. Habíamos comenzado en nuestro ensayo por contrastar algunas de las diferentes definiciones filosóficas a lo largo de la historia, y ahora hemos acabado hablando del horizonte de la muerte y del sentido de la vida. Esto requiere una aclaración. Debemos distinguir, pues, entre lo que son las teorías físicas y filosóficas que intentan abordar el problema de la realidad "objetiva" del tiempo, y, por otro lado, lo que sería el tiempo como experimentado y vivenciado. En el libro de Jean Améry (1968), se ve clara está distinción de la que estamos hablando, así como la artificialidad de su frontera. "A", el protagonista del libro de Améry (1968), está preocupado por el envejecer, por la experiencia del paso del tiempo, por el peso de los sedimentos que deja el tiempo en su pasar y que cada vez estrecha más su horizonte de vida. Además, "A" tiene la sensación de que el tiempo, casi insensiblemente, se le ha escapado de las manos, se ha desvanecido, ha pasado demasiado rápido. Entonces "A" busca respuesta en el hombre de ciencia, en el físico, pero su amigo el físico, para quien el tiempo es definible y expresable por medio de fórmulas y no reviste mayor misterio, no le puede ayudar. "A" habla del "paso de los años" y del "peso de la muerte", y ninguna descripción física y objetiva del tiempo le puede consolar. Sin embargo, su amigo el físico, que tan seguro de sí mismo y de su ciencia se sentía, resulta que también es un hombre de carne y hueso que envejece. "Mucho tiempo después -'A'- vio de nuevo a su amigo, en un momento en el que se hallaba cansado y deprimido, y mucho menos dispuesto a la concreción optimista. ¡Qué deprisa se me ha pasado el tiempo!, dijo el científico. ¿Cuánto hace que nos conocemos? ¿Veinte años? ¡Santo cielo!, ¡cuantos proyectos tenía entonces, cuántas cosas pensaba hacer que luego no he hecho! Y cuántas quisiera hacer ahora, si tuviera tiempo. Pero el tiempo ha pasado, incluso demasiado y me queda tan poco. ¡Oh tiempo extraño, tiempo consumado!" (Amery, 1968: 21).

\footnotetext{
${ }^{4}$ Nótese que la melancolía asociada al paso del tiempo, así como el tema del tiempo en general, es un aspecto central para la literatura: el tiempo es un tema poético-existencial por excelencia. No sin razón se dice que el talento del genio y del escritor tiene que ver con su melancolía, y, precisamente, siempre se ha asociado a la melancolía con Saturno, con el Padre Tiempo. Por eso siempre se decía que los sujetos sometidos al influjo de Saturno "podían ser sabios, pero no felices. Los hombres nacidos bajo Saturno estaban condenados a la melancolía" (Panofsky, 1972: 100-101). Por lo demás, cabe advertir, es cierto, que no pocas veces nos dejamos llevar en nuestras reflexiones por la estética del tiempo, siguiendo en estos casos la máxima de Novalis, a saber: "cuando más poético, más verdadero".
} 
Vemos pues aquí, la transición quizás metodológicamente incorrecta, pero humanamente necesaria, entre el intento objetivo de acercarse al tiempo y la experiencia personal de vivir el propio transcurso del tiempo. Desde luego, en el libro de Améry (1968) no encontraremos afirmaciones propias de las ciencias positivas -"no he podido aspirar a nada semejante". En efecto, en su reflexión acerca del envejecer, digámoslo así, le interesan las experiencias del espíritu, mientras que no le interesaría en demasía, por ejemplo, el dato cronobiológico que asegura que la causa del envejecimiento reside en la corrosión de los telómeros o extremos de los cromosomas. La consecuencia de aplicar en filosofía una u otra tendencia deja notar su paso. Cuánto más importancia le demos a las experiencias del espíritu más cerca estaremos de una filosofía vitalista y de una filosofía de la conciencia. Mientras que cuánto más reacios seamos a acercarnos al tiempo de una manera, en principio, tan poco objetiva como la expuesta por Améry, más tenderemos hacia una filosofía positivista y analítica.

De forma similar, señala Paul Ricoeur (1979a) la distinción entre los filósofos analíticos -más preocupados por "reducir nuestro hablar sobre el tiempo a un minimum conceptual- y los filósofos reflexivos -más preocupados por elevar nuestra experiencia del tiempo a un maximum espiritual" (Ricoeur, 1979a: 11). Y el mismo añade: "No es que el filósofo analítico y el reflexivo se contradigan. Es, más bien, que no se encuentran. Uno se interesa... por nuestro 'hablar sobre' el tiempo; el otro, por nuestra 'experiencia profunda' del tiempo. Esto motiva que el problema del uno sea el minimun; y el del otro, el maximum. El uno tiene en cuenta la economía conceptual; el otro, la intensidad espirirtual". (Ricoeur, 1979a: 11).

En este libro, El tiempo y las filosofías, presentado por Ricoeur y que recoge un abanico importante de perspectivas expuestas por diversos autores -que es precisamente lo que estamos tratando de mostrar en este apartado-, podemos encontrar desde la corriente filosófica occidental hasta la filosofía Zen, pasando por una sociología de las patologías del tiempo o por una temporalidad encarnada en adivinos, profetas, futurólogos, etc. "La presente obra testifica la diversidad y riqueza de las interpretaciones del tiempo", reza en la contraportada. Para dar cuenta de semejante disparidad y diversidad en lo que atañe al tiempo, es normal que existan metodologías diferentes desde el meditabundo hasta el analítico-, o bien un autor simplemente puede elegir una época o una cultura como testigos. En este último sentido cabría destacar también el libro Las culturas y el tiempo, obra también presentada por Ricoeur (1979b) que está más centrada en las diversas concepciones culturales del tiempo -griega, china, hindú, cristiana, etc. Acerca de esta diversidad y riqueza de filosofías y de culturas que versan sobre el tiempo, aunque brevemente, también tendremos que dedicarles unas palabras de atención. Porque desde luego, como vamos a ver, no es igual la temporalidad occidental -abstracta, lineal, medible, homogénea, etcétera- que, por ejemplo, la temporalidad china -capaz más bien de saborear el tiempo de cada proceso.

Desde mi punto de vista, dado que los seres humanos culturales no podemos situarnos inmediatamente en contacto directo con el devenir, necesitamos entonces, entre otras cosas, del tiempo para que ejerza de retícula o "lentilla" desde la cual visualizar humanamente un mundo habitable para nosotros. Pero eso sí, desde luego, esta lentilla de tiempo del hombre de cada cultura particular, estará teñida de los colores específicos de acuerdo con los propios códigos culturales y estructuras simbólicas. Esta lentilla de tiempo, por lo demás quizás universal a todo ser humano social, viene en efecto coloreada según época y cultura. Y es por ello que, auque sea de esperar que toda cultura humana exprese una cierta sensibilidad para con el tiempo, no podemos esperar sin embargo que todas las culturas y épocas lo expresen de la misma manera. 
Pero vayamos al grano. Lo primero que hay que decir, a modo de advertencia, es que en la filosofía de cada cultura no hay un único tiempo en juego. Ahora bien, a pesar de que nuestra tradición alberga diversos tiempos, en líneas generales podemos hablar de una conjunción entre la herencia griega y la herencia hebrea que da lugar a un tiempo propiamente occidental. En efecto, "de la conjunción entre la herencia griega (abstractiva y ávida de regularidades) y la tradición hebrea (lineal y orientada, como corresponde a un pueblo nómada que, instalado en la historia, avanza hacia un eschaton) sí puede hablarse grosso modo de un tiempo occidental: abstracto, homogéneo, lineal, progresivo, orientado, medible" (Lizcano, 1992: 59-61). Pues bien, si contrastamos este ideal de tiempo con, por ejemplo, el tiempo de la cultura china, encontramos entonces importantes diferencias. Lizcano (1992) destaca varias diferencias. La primera de ellas consiste en que el tiempo occidental es un tiempo enajenado, un tiempo abstraído de las cosas, separado de ellas para luego imponerse a ellas desde fuera, mientras que, por el contrario, el tiempo chino, grosso modo, es un tiempo interior al las cosas, que brota desde dentro de los procesos y de las situaciones. Otra característica distintiva consiste en que el tiempo en la lógica china es un tiempo que chisporrotea. Es decir, que si en la lógica occidental el tiempo que no goza del visto bueno del principio de no contradicción es un tiempo que se revela, a la postre, como tiempo falaz, perdido, sin sentido y des-dichado, por el contrario, en la lógica china, las figuras de la contradicción se desgranan y chisporrotean "en imágenes de difusión y dispersión: escarcha, vapor, arena, bruma, flores... o caracteres escritos en la superficie del agua. La contradicción china no pierde el tiempo, lo multiplica en un enjambre de tiempos propios" (Lizcano, 1992: 64). Otra característica distintiva consiste en que, así como el tiempo occidental es un tiempo encadenado por la causalidad, objetivado por un observador cronometrante y ávido de quietud y estabilidad, el tiempo chino, acoge la casualidad, acepta el devenir y hace del observador un partícipe.

Otras intuiciones básicas acerca de la percepción y experimentación china del tiempo, en contraste con el tiempo occidental, podemos encontrarlas en el artículo de Claude Larre (1979: 37, 66): "Percepción empírica del tiempo y concepción de la historia en el pensamiento chino". En este texto Larre comienza por hablar de algo así como el sabor del tiempo en la experiencia china: "Se sabía apreciar la cualidad del tiempo, como se apreciaba el té, el papel, la seda, las mil comodidades de la existencia. El tiempo llegaba, pasaba, volvía a llegar. El tiempo de la rama del ciruelo, del tallo de bambú, de la hoja de arce, del ramaje de pino; el tiempo del grito agrio del pato gris, del dulce canto de la oropéndola, del reclamo de la codorniz. Tantos sabores y perfumes que, mezclados con la conciencia, situaban cualitativamente el tiempo" (Larre, 1979: 38). En esta sensibilidad para con el tiempo por parte de la cultura china existe, como vemos, una atenta mirada de la naturaleza y de sus ciclos, de sus estaciones, de sus meses. Así, a cada una de las estaciones del año, a cada uno de sus meses, le corresponde un olor, un sabor, un perfume, un color, un sonido específico... Existe además un cierto ocasionalismo chino, de forma que, cuando se actúa, se procura "ver al máximo posible la tendencia que, de un instante a otro, va a provocar una nueva forma en el interior de los soplos y, mediante un ligero movimiento, colocarse en posición para sacar provecho" (Larre, 1979: 47). Podríamos decir, pues, que por encima de la medición de la cantidad exacta del tiempo, lo verdaderamente importante es captar la calidad del momento y estar atento -digámoslo así- a la oportunidad, al momento justo en el que el viento puede soplar en nuestro favor. En fin, como podemos apreciar, la temporalidad china, en armonía con el tiempo cósmico, es muy sensible a los detalles y aprecia, muy por encima del aspecto meramente cuantitativo del tiempo, su aspecto cualitativo. 
Por otro lado, también en el pensamiento de la tradición de la India, encontramos muchas intuiciones diferentes a propósito del tiempo y en disonancia con el tiempo occidental. Dentro de estas diferentes tendencias e intuiciones que el pensamiento indio adoptó para con el tiempo, llaman nuestra atención aquellas que tienden a la supresión del tiempo, es decir, aquellas que "tienden, teóricamente, a negar cualquier valor real del tiempo e intentan llegar, en la práctica, a un estado de existencia más allá del tiempo. En términos propios del yoga al 'cese de los estados mentales', de los que forma parte el tiempo" (Panikkar, 1979: 80). Se trata, pues, de una especie de reducción psicológica del tiempo que muestra la no existencia del tiempo en sí, de forma que, a través de esta abolición del tiempo, se hace posible la iluminación. "Esta reducción [en el yoga Vâsishtha]... pretende demostrar el carácter irreal de los instantes y de las edades cósmicas. Según el estado mental del sujeto, dice, un instante puede aparecer como un kalpa (eón), o por el contrario, un eón puede ser vivido como un solo instante. En suma el tiempo no existe en sí. Quien se absorbe en la meditación, no conoce ni día ni noche y, finalmente, el conocimiento de sí, la iluminación, engloba en un instante todo el devenir" (Panikkar, 1979: 80). Sin duda, en Occidente, a nuestra manera, también hemos sido sensibles a esta clase de reflexiones acerca del ser o no-ser del tiempo y acerca de su dilatación.

\section{Del tiempo de los "arcaicos" y el tiempo de los modernos"}

Una clasificación más general todavía sería la del tiempo de los hombres arcaicos respecto al tiempo de los modernos. Esta distinción viene patrocinada por Eliade y es una de las tesis fundamentales de su bello libro El mito del eterno retorno (1949). Este libro, dice Eliade, "interroga las concepciones fundamentales de las sociedades arcaicas que, pese a conocer también cierta forma de 'historia', se esfuerza por no tenerla en cuenta. Al estudiar esas sociedades tradicionales, un rasgo nos ha llamado principalmente la atención: su rebelión contra el tiempo concreto, histórico; su nostalgia de un retorno periódico al tiempo mítico de los orígenes, al Tiempo Magno... A nuestro parecer, estamos autorizados a ver en ese menosprecio de la historia, es decir, de los acontecimientos sin modelo transhistórico, y en ese rechazo del tiempo profano, continuo, cierta valoración metafísica de la existencia humana" (Eliade, 1949: 9-10).

Si Eliade lleva razón, para el hombre arcaico, la realidad es tanto más real, y las acciones están tanto más dotadas de sentido, en la medida en que se participa de lo sagrado, en la medida en que se regresa al illo tempore, ab origine, es decir, en la medida en que se regresa al tiempo primordial de los orígenes y se repiten las mismas acciones que fueron llevadas a cabo entonces por los dioses y por los héroes. En efecto, el hombre arcaico intenta escapar del tiempo concreto y profano en virtud de purificar y reciclar periódicamente su espíritu y su sufrimiento. Por ello, "para las sociedades tradicionales, todos los actos importantes de la vida corriente han sido revelados ab origine por dioses o héroes. Los hombres no hacen sino repetir infinitamente estos gestos ejemplares y paradigmáticos" (Eliade, 1949: 38).

Frente a esta nostalgia hacia el tiempo auroral y frente a esta necesidad de abolir el tiempo, de salir del tiempo concreto y profano, frente a ello, Eliade contrapone el tiempo moderno como un tiempo dominado por el terror de la historia. El sufrimiento del hombre moderno, se queja Eliade, el terror de la historia -de las catástrofes, de las guerras, etcétera- no puede ser consolado e higienizado en el tiempo límpido y auroral de los orígenes. En cambio, las grandes concepciones arcaicas -y no tan arcaicas- del tiempo, eran capaces de encontrar un sentido al sufrimiento, ya sea porque los males eran fruto de un designio divino que al final los remediaría; o ya fuera que los males se debieran a 
que nos había tocado nacer y vivir en una fase decadente del gran círculo del tiempo -pero a sabiendas de que esta gran rueda está ya apunto de cerrarse y purificar el todo-; o ya fuere como fuere. Pero el caso era que, el hombre arcaico, encontraba así una justificación al sufrimiento y a los temores de sus vidas. Mientras que el hombre moderno, se encuentra machacado por el terror de los acontecimientos de la historia. Esta tesis de Eliade, como vemos, es una tesis arriesgada -casi visceral- que sugiere toda una serie de reflexiones y plantea no pocos interrogantes a su alrededor.

¿A qué se refiere Eliade exactamente cuando habla del horror de "la historia" en el "hombre moderno"? ¿Y por qué este hombre moderno está indefenso frente a la historia? ¿Acaso el hombre moderno carece de mecanismo válidos para luchar contra el sufrimiento que la historia deja a su paso? Más aún: ¿eliminaba de veras el sufrimiento el arcaico simplemente bañándose en el límpido tiempo auroral?

Para responder a estas interesantes cuestiones, pienso que es imprescindible comprender la psicología de Eliade y ser conscientes del contexto en el que se gestó la tesis del terror de la historia. De hecho, si en primer lugar atendemos a su psicología, enseguida nos damos cuenta de que el problema del tiempo salpica prácticamente todos los estratos de su pensamiento y de su existencia. Desde su filosofía hasta su literatura, pasando por sus relaciones amorosas o sus fobias personales, Eliade se nos presenta como un ser absolutamente obsesionado por el tiempo -e incluso podríamos decir que Eliade vive enfermado por el tiempo, que está enfermo de tiempo. Me refiero concretamente a la obsesión patológica de Eliade por regresar a la nostalgia de los tiempos pasados, ya sean los de su juventud pasada y sus primeros amores -como por ejemplo Maitreyi-, o ya sean las épocas pasadas de la humanidad, épocas en las que el mundo todavía estaba encantado, cuando todavía las cosas estaban llenas de dioses.

Quizá para nosotros, hombres modernos, que vivimos inmersos en la celeridad de la sociedad digital, de la innovación obligada y de la soledad electrónica, quizá a nosotros que vivimos en el nihilismo cumplido, tal vez nos resulte difícil comprender esa nostalgia por los orígenes. Pero en realidad, todos podemos comprender en el fondo ese prestigio de los orígenes. Nosotros mismos, filósofos, no podemos dejar de volver a Grecia. Allí fue donde por primera vez se enamoró Occidente de la Sabiduría. Hay, pues, un enamorarse de los orígenes al modo de una nostalgia del primer amor.

Por otro lado, si queremos atender al contexto en el que se gestó la tesis del "terror de la historia" en El mito del eterno retorno, entonces tendremos que consultar su Diario portugués (1958). Este diario es alimentado por Eliade entre los años 1941 y 1945, precisamente en el dramático escenario de la 2a Guerra Mundial, el exilio en Portugal que le toca vivir, y la muerte de su esposa Nina. Y precisamente en este contexto trágico es donde entra en controversia con el historicismo a través de su tesis del "terror de la historia". Al respecto, se dan toda una serie de comentarios muy reveladores en su Diario portugués y que a continuación transcribimos en orden cronológico:

"Estamos viviendo una catástrofe cósmica; este es el único sentido de la guerra. Tengo que verla como veían mis antepasados la sequía, los terremotos o las epidemias... Se muy bien que estoy viviendo el final de un ciclo..." (Eliade: 1958: 45-46). "Descubrir, como se descubre el pensamiento moderno desde Dilthey en adelante, que el hombre es y permanece siempre en la historia, es más grave y más dramático de lo que parecería a primera vista. La réplica a este descubrimiento es la desesperación" (Eliade: 1958: 97). "Estoy pensando en escribir un libro, El horror de la historia, con este tema: que hasta hace muy poco, cualquier drama personal y 
catástrofe étnica encontraba su justificación en cierta cosmología o soteriología (los ritmos cósmicos, la reabsorción en el agua, la ecpirosisia o purificación por el fuego, "nuestros pecados", etc.). Ahora, la historia aterroriza sencillamente porque las tragedias provocadas por ella ya no encuentran justificación ni absolución" (Eliade: 1958: 123). "Cosmos e historia únicamente plantea la cuestión antropológica de la desesperación del hombre moderno, al que le faltan mitos vivos que le puedan justificar, explicar o recompensar los sufrimientos, decepciones e injusticias soportadas a causa de la historia. Pero no sólo es esta cuestión del "terror de la historia" la que exige resolución, sino también la otra, tan urgente como ella, de la reconciliación del hombre por el tiempo, de su salvación por el simple hecho de participar en un cosmos temporal, rítmico y rico en alternancias" (Eliade: 1958: 216). [Cabe apuntar también que cuando Eliade habla aquí de El horror de la historia o de Cosmos e historia se está refiriendo a lo que en un futuro será El mito del eterno retorno].

A raíz de lo dicho, pienso que ahora podemos comprender mejor la intención de Eliade y responder mejor a las cuestiones que nos habíamos planteado. La historia o historicismo del hombre moderno que Eliade critica es la historia que finalmente no tiene un sentido transhistórico (metahistórico) que purifique el sufrimiento y consuele de alguna manera al hombre. "¿Cómo puede ser soportado el terror 'a la historia' en la perspectiva del historicismo?... ¿cómo podrá el hombre soportar las catástrofes y los horrores de la historia -desde las deportaciones y los asesinatos colectivos hasta el bombardeo atómico- si, por otro lado, no se presiente ningún signo, ninguna intención transhistórica..." (Eliade, 1949: 138).

Según Eliade, desde Hegel las desgracias comienzan a justificarse -cada vez con mayor frecuenciacomo necesidades del momento histórico. Con Hegel todavía se puede explicar el mal histórico como manifestación del Espíritu Universal, porque todavía se conserva algo de la tradición judeocristiana el destino de un pueblo conserva todavía una significación transhistórica. Sin embargo, para Eliade, incluso "hay que ir más allá: descifrar su significación simbólica. Porque cada acontecimiento cotidiano comporta una significación simbólica, ilustra un simbolismo primordial, transhistórico y universal... descifrar la significación simbólica secreta de los acontecimientos históricos puede constituir una revelación, en el sentido religioso de la palabra" (Eliade, 1982: 12). En efecto, Eliade, mediante la descodificación de lo que de religioso existe en la cotidianidad, le gustaría romper la corteza de los acontecimientos para abrirlos a lo universal, descifrar la significación simbólica trasnhistórica de todos los incidentes. O dicho con sus palabras: "Creo que lo transhistórico está siempre camuflado en lo histórico, lo extraordinario en lo ordinario... Es cierto que esta realidad gris, esta cotidianidad, oculta otra cosa. Tal es mi convicción profunda" (Eliade, 1979: 169).

En cualquier caso, démonos cuenta de lo problemático de las afirmaciones de Eliade. Porque en sus insinuaciones que apuntan hacia una nostalgia del sentido histórico, a modo de una metafísica de la historia, a modo de una metahistoria de tipo hegeliano, o a modo de un sentido teológico y teleológico tipo temporalidad judeocristiana, en todos estos casos, en cualquier momento le pueden abordar en el camino todos esos pensadores que han decidido romper con la metafísica del sentido de la historia -pensemos por ejemplo en la Dialéctica negativa de Adorno y en su negativa a dotar de sentido y justificación metahistórica a la barbarie del Holocausto.

Por otro lado, para Eliade, los mecanismos del hombre moderno para luchar contra el sufrimiento son inútiles y desesperanzadores. Eliade parece no aceptar la visión desencantada del mundo y, 
evidentemente, deja que sus presupuestos íntimos -su obsesión nostálgica, su pasión por lo sagrado, sus creencias cristianas, la $2^{\text {a }}$ Guerra Mundial, la enfermedad y muerte de Nina, sus rezos de súplica, etcétera- influyan en su tesis del "terror de la historia". Por lo demás, habría que preguntarle también a Eliade si para los hombres arcaicos y del sentido transhistórico era y es tan sencillo lavar realmente el sufrimiento personal e histórico. ¿Acaso bastaba con bañarse en el límpido tiempo auroral para salir como nuevo? ¿Acaso bastaba, por ejemplo, con remitir los males, los asesinatos, las masacres y tantas otras cosas a la voluntad de Yahvé?

En mi opinión, Eliade se equivoca al ver al hombre moderno desamparado y desprovisto de mecanismos para hacer frente a los sufrimientos históricos. Sin embargo, por otro lado, pienso que es cierto que los métodos de los hombres arcaicos eran más efectivos y consoladores, y ello, por ser más viscerales y primitivos, menos rebuscados, más felizmente "ingenuos". Y precisamente esa potencia es lo que hace fuerte la intuición de Eliade, eso y quizá también una cierta añoranza de sentido y de magia en el mundo.

Por otro lado, pienso que resultaría interesante llevar a cabo una especie de inventario con los restos de las tradiciones e intuiciones que todavía persisten en nuestras vidas y que son capaces de, en cierta medida, abolir el tiempo y purificar las faltas y los sufrimientos. Estoy pensando por ejemplo en las fiestas del cambio de año, en donde todavía decimos aquello de "Año Nuevo, Vida Nueva" y comemos las 12 uvas de la suerte que reparten fortuna a los 12 meses venideros. En estas épocas se celebra universalmente, en efecto, la muerte del tiempo y su posterior regeneración. Pero no sólo me refiero a este gesto tan paradigmático, sino también a todo ese conjunto de gestos cotidianos en los que todavía pudieran esconderse ciertos mecanismos de corte arcaico purificadores del sufrimiento, desde darse una ducha antiestrés hasta leer un libro o disfrutar de las proezas de los héroes de las películas. De alguna forma, el mundo desencantado y secularizado todavía conserva ciertas estructuras arcaicas. O dicho de otra manera, quizás por debajo de la gran parafernalia moderna todavía palpiten con fuerza unas estructuras arcaicas que no hacen sino reflejar el miedo a la libertad y a la autonomía, así como también el miedo antropológico a la muerte como límite del tiempo del transeúnte vital.

\section{Del tiempo a través de los instrumentos que lo miden}

Otra perspectiva muy interesante desde donde abordar el problema del tiempo -si es que es un problema-, podemos encontrarla en la original manera en que nos la presenta Juan David García Bacca. Este autor se pregunta "en qué objetos especiales y en qué aparatos ha tratado el hombre con el tiempo y qué definiciones ha sacado de 'El Tiempo' según lo que el trato con tales objetos y aparatos le iba delicadamente diciendo" (García Bacca, 1947: 15, 48). García Bacca pretende explicar las distintas definiciones filosóficas que del tiempo se han dado en función de los instrumentos que existían en cada caso para medir el tiempo. Sería algo así como: dime con qué aparatos de medición del tiempo andas y te diré qué definición del tiempo me darás. Démonos cuenta, por lo demás, que para mantener esta posición hay que defender, casi a toda costa, que la invención material del instrumento precede a la definición filosófica, y no a la inversa: "No se crea que los relojes vulgares de sol en que el tiempo se presenta vestido de movimiento del astro rey... se hayan hecho después de que Aristóteles, u otro filósofo, hubiera fijado las condiciones para una caracterización esencial del tiempo. La inversa es más probable: la invención técnica de relojes de sol... ha precedido y guiado la invención de la definición de tiempo, encontrada por el entendimiento 
en los relojes, instrumentos en que la vida había ya hasta cierto punto separado el tiempo de las cosas naturales, presentándolo de una peculiar manera" (García Bacca, 1947: 27-28). Dicho esto, García Bacca, brevemente, parte de la invención de los artilugios que miden el tiempo -desde el reloj de sol hasta el reloj atómico todo y pasando por los relojes de gravitación y los relojes de resorte-, para luego, desde esta base material, comprender las definiciones filosóficas que acompañan a estos instrumentos -desde Aristóteles a Bergson.

Y además, García Bacca anuncia novedades interesantes en la evolución de estos instrumentos y, por ende, del pensamiento que versa sobre el tiempo reflejado en ellos: "En el reloj de sol, quien manda es el sol. Vamos a ver que la evolución no sólo técnica sino del concepto mismo de tiempo consistirá, cada vez, en que el hombre construya aparatos artificiales, con fuerzas naturales en estado artificial también, de modo que pueda mandar él, el hombre, en el tiempo" (García Bacca, 1947: 19).

Desde esta perspectiva o modo de tratar el tiempo que nos presenta García Bacca, y siguiendo con lo dicho por él, resulta que las definiciones filosóficas que del tiempo dieron Platón y Aristóteles reflejan como un calco teorético lo que les desvela el reloj de sol. El reloj de sol abstrae los aspectos concretos y nos presenta el movimiento en un estado puro, espectral, geométrico. Así, el movimiento visto a través del reloj de sol, nos da, dice García Bacca (1947: 28): "una pura lección geométrica, describiendo rectas mayores o menores, deslizándose por los ángulos. Por eso... habrá que darle un nuevo nombre, porque ya no es movimiento del sol ni movimiento que mueva nada real ni movimiento que pueda chocar; y el nuevo nombre será el de Tiempo... Tiempo es, por tanto, movimiento geometrizante, lección de geometría que el movimiento da en un instrumento". Según esta interpretación de García Bacca, las definiciones de Platón y Aristóteles deben por tanto reflejar, y no por casualidad, esa lección básica de geometría que nos enseña el reloj de sol. Y por eso para Aristóteles, en efecto, el tiempo será numeración del movimiento según el "antes" y el "después". Y asimismo, para Platón el tiempo será como el rastro geometrizante que la eternidad deja en su andar según número por el mundo sensible. Y así, ambas definiciones calcan a pedir de boca -según esta interpretación- la experiencia que el reloj de sol enseña a la mente del filósofo.

Ahora bien, cabe destacar en tono polémico que, según García Bacca (1947: 30): "El único elemento que, con nuestra terminología, podríamos encontrar de subjetivo -en Aristóteles- provendría de esa numeración o graduación geométrica elemental que nosotros hacemos y señalamos en los aparatos, y sólo por este motivo dice Aristóteles que interviene el alma en el tiempo". Sin embargo, seguramente habría que discutir y matizar mucho esta afirmación. Para empezar habría que señalar que la perspectiva subjetivista de Aristóteles es más rica y compleja de lo que a primera vista pudiera parecer, y que ésta no se encuentra únicamente en los tratados físicos sino también en sus reflexiones éticas y psicológicas, siendo en realidad Aristóteles el precursor tanto de la perspectiva objetivista como de la subjetivista, y, de hecho, buena nota tomará San Agustín de estas reflexiones aristotélicas a la hora de presentar su idea del tiempo como distensión de alma. Ciertamente la influencia del reloj de sol en las teorías de Platón y Aristóteles debió de ser un factor importante. Pero no por ello podemos decir que la definición, por ejemplo, del tiempo como "imagen móvil de la eternidad", de Platón, se deba únicamente a la lección geométrica del reloj de sol, pues también tendrá que ver, para empezar, con su teoría de las ideas y de las sombras -a no ser que queramos decir que también la teoría de las ideas es una metáfora extraída del reloj de sol, y que por eso la figura del sol juega un papel fundamental y emanante en la filosofía de Platón, lo cual sería ciertamente una reflexión tan deslumbrante como imposible de sostener. En definitiva, que la lección 
geometrizante del reloj de sol, no deja de ser sino una explicación parcial y no puede ser la causa única y suprema que configura la teoría del tiempo en Aristóteles o en Platón, si bien, en efecto, debió de ser un factor de influencia acaso importante. Pero no seamos tan quisquillosos y dejemos que García Bacca continúe con su ensayo brillante acerca del tiempo.

Por otro lado, para García Bacca, los relojes de sol no son, en consecuencia, susceptibles de despertar en las mentes filosofantes el aspecto subjetivo del tiempo, ya que, como es sabido, los relojes solares son públicos y cósmicos. Y por tanto, el tiempo que descubrirán en ellos los teóricos del tiempo será un tiempo objetivo, universal y cósmico. $Y$ también ocurrirá lo mismo con los relojes de arena, de agua o de péndulo, pues a pesar de su mayor complejidad, en todos ellos sigue siendo la clave de su funcionamiento una fuerza cósmica y universal que se impone desde fuera extrasubjetivamente, a saber, la gravedad.

Bien distinta será la situación cuando aparezcan en escena los relojes mecánicos, el tiempo del resorte. Estos aparatos ya son, según García Bacca, plenamente artificiales y no dependen ya ni del sol ni de la gravedad, sino que dependen sobre todo del hombre, que es el que les da cuerda para que sigan latiendo. Y así, "con el consiguiente aumento de la intimidad del tiempo en el hombre: llevamos ya el tiempo en el bolsillo. $Y$ sin broma podemos decir que estos relojes 'andan cuando anda el amo', pues el hombre, como dueño y señor, ha obligado al tiempo a que se manifieste en un aparato completamente artificial y puede manifestársele a uno solo de los individuos, a cada uno... Con los relojes de resorte el tiempo ha pasado ya a ser objeto de uso individual, en ser persornal. $Y$ no es casual que precisamente en tiempos del subjetivismo europeo, en su apogeo sobre todo, haya llegado a su perfección fundamental el reloj de resorte: el reloj que da el tiempo al individuo" (García Bacca, 1947: 21).

Sin embargo, el tiempo subjetivo es un descubrimiento que con frecuencia se le atribuye a San Agustín, y así lo reconoce García Bacca. Pero entonces, pienso que habría aquí que preguntarle a García Bacca cómo es posible que San Agustín descubriera el tiempo subjetivo si todavía no vivía en la época de los relojes de resorte. García Bacca entiende que San Agustín no era un hombre de su tiempo, sino un hombre de una altura histórica muy superior, equivalente acaso a la de Kant. No obstante, la pregunta sigue en pie. Recordemos que, según la interpretación de García Bacca, no ocurre que la idea filosófica preceda al invento técnico, sino a la inversa. Y recordemos también que, según esta interpretación, Aristóteles definió el tiempo como "el número (orden) del movimiento", atendiendo a la lección de geometría que le enseñaba el reloj de sol de García Bacca. Pues bien, por la misma regla de tres, hay que preguntarse qué aparato hizo que San Agustín, antes de la época de los relojes de bolsillo, vislumbrara el tiempo como distensión del alma. En el caso de San Agustín nos encontramos ante una clara excepción, pues este autor queda al margen de su explicación, y ello pese a que San Agustín es un pensador crucial que es considerado por García Bacca como el descubridor del tiempo subjetivo. Al parecer, la tesis de García Bacca, pese a su originalidad y pese a guardar cierto grado de verdad, es una tesis que cojea en ciertos puntos.

Por otro lado, otro punto débil del razonamiento de García Bacca, consistiría en esa supuesta "completa artificialidad" de los relojes de resorte: pero, ¿acaso estos instrumentos no obedecen a leyes naturales? Más aún, también habría que señalar que ciertamente no es del todo correcto afirmar que estos artilugios mecánicos, pese a ser enseres íntimos de bolsillo, reflejen un tiempo subjetivo: ¿o es que acaso no marcan una hora objetiva para todos? 
De todas formas, no debemos tomar estas objeciones a modo de refutaciones rígidas, simplemente se trata de matizar ciertos puntos que no quedan claro. Como ya digo, la perspectiva de García Bacca encierra ciertos grados de verdad, y de hecho, el poder tener el tiempo en el bolsillo, aunque sea el mismo para todos, el poder consultar privadamente el tiempo en nuestro reloj privado, ello sin duda contribuye en cierto sentido a interiorizar el tiempo en nuestras mentes.

Pero en realidad -permítanme que deje volar la imaginación-, para fabricar un reloj verdaderamente subjetivo que fuera más o menos útil, tendríamos que inventar un artefacto que tuviese conectadas y en armonía sus saetas con el alma misma y el pensamiento, y también con los procesos fisiológicos que ocurren en nuestro cuerpo, de forma que, este fantástico reloj, fuera sensible a nuestro carácter y a nuestra forma de vivir los momentos y, por ende, fuera capaz de acelerar o pausar las manecillas del segundero, del minutero e incluso de las horas mismas. Y si además quisiéramos, como decíamos, que aún con todo fuera en alguna medida útil intersubjetivamente, estos artefactos tendrían que, al final del día más largo, sincronizarse en el sopor de la noche, en el sueño, de tal suerte que, cada mañana seguiría cantando el mismo gallo en cada uno de nuestros relojes. $Y$ es que, claro, para que este reloj fuese razonablemente útil, tendría que tornarse objetivo a la hora del sueño, ya que, en el mundo onírico, los espacios y los tiempos se alborotan en demasía, y quizás algunos se levantarían ya con las sienes emblanquecidas, en otro siglo, envejecidos y moribundos. Pero dejemos estas ficciones que son más propias de un relato de ciencia ficción y continuemos con el tema que nos traemos entre manos. En cualquier caso, añadir a todo lo dicho que, los relojes, en rigor, no son ni objetivos ni subjetivos, sino ante todo sociales.

Bien, todas estas matizaciones que hemos anotado en contra de la argumentación de García Bacca, en realidad, en mi opinión, se deben a que descansan sobre una premisa de partida que privilegia absolutamente el invento técnico "material" por encima del pensamiento, de forma que la reflexión teórica queda determinada -en vez de condicionada en cierta medida. Sin embargo, sería más adecuado mantener una posición intermedia, ya que, decir que los inventos técnicos preceden a los pensamientos filosóficos es, tan a veces falso y tan a veces cierto, como la postura inversa, a saber, que los pensamientos filosóficos preceden a los inventos tecnológicos. Quizá, pues, sería más acertado decir que, en general, entre estas dos tesis antagónicas existe una relación bidireccional de influencia mutua, es decir, que se trata de una relación de ida y vuelta, o si se quiere, que ambas caminan juntas cogidas de la mano. En cualquier caso, hay que agradecer a García Bacca que, digámoslo así, realice este estirón desde el otro lado de las razones, llegándose así a un equilibrio general más adecuado, pues ciertamente la idea del filósofo abstracto que saca una definición límpida del tiempo desde la pureza de su pensamiento, es sin duda una concepción errónea de cómo nacen las ideas filosóficas del pensamiento.

Dejemos sin embargo a un lado el aburrimiento de las objeciones y sigamos con la exposición del texto de García Bacca. Decíamos que los relojes de sol y luego los de arena, agua o péndulo, todavía no habían dado pie a una nueva concepción filosófica del tiempo -excepto en el caso de San Agustín, que se adelanta a su época y es el precursor del tiempo subjetivo-. Sin embargo, con la aparición del tiempo de resorte, del tiempo del reloj mecánico (artificial), sí que se abrirá ya efectivamente un nuevo horizonte en donde contemplar un tiempo diferente, un tiempo que tiende a ser privado y de bolsillo, un tiempo que despertará en las mentes filosóficas la faceta subjetiva de la temporalidad. Por lo demás, quiero recordar al lector que, en efecto, la aparición del reloj mecánico supuso una gran revolución: "La etapa crucial en este desarrollo fue la invención del reloj mecánico en Europa occidental hacia finales del siglo XIII. A pesar del misterio que todavía rodea al acontecimiento, sus 
consecuencias fueron trascendentales e influyeron de modo fundamental en el papel dominante del tiempo en la civilización contemporánea" (Whitrow, 1988: 10).

Un tiempo propiamente moderno es, pues, el tiempo como distensio animi de San Agustín, un tiempo más privado y más humano -más del hombre- que es una especie de resorte anímico capaz de contraerse y dilatarse haciendo que los acontecimientos del mundo exterior se me presenten como pasando más deprisa o como pasando más lentamente. "El tiempo es, por tanto, espejo de doble cara; por la interior hace que el alma note el ritmo como le pasan las cosas internas; por la exterior obliga a que los objetos externos desfilen al mismo compás que los sentimientos internos" (García Bacca, 1947: 32). De suerte que, la distensión del ánimo, por lo general, permanece en un estado cotidiano -dice García Bacca-, gracias a lo cual, en este término medio se hace posible que los sucesos internos y externos de todos los hombres parezcan concordantes. La metáfora que aquí se utiliza para comprender mejor lo dicho, es una metáfora de agua: el agua puede evaporarse o helarse, pero cotidianamente la encontramos en su estado líquido, en un estado cotidiano $-\mathrm{y}$ lo mismo ocurre con el tiempo, que es como el agua.

Por otro lado, siguiendo esta línea agustiniana, llegamos a Kant y comprobamos que, también para él: "el tiempo es una cierta forma del ánimo, una forma a priori de la sensibilidad; sólo que tal forma es rígida, está siempre en la misma tensión o grado de dilatación, pues, dadas las preferencias que Kant, como hombre de su tiempo, sentía por la ciencia, por lo programáticamente universal y supraindividual, tendía a dar a la forma de tiempo, a la tensión del ánimo, un grado fijo, estable, lo más amplio posible; dar al resorte cuerda de una vez para siempre, sustrayéndolo así de las arbitrariedades de la vida acientífica, de la común y corriente; pero, a semejanza de San Agustín, el tiempo resulta 'animi distensio', distensión del ánimo, forma a priori, con el oficio de hacer que tanto los sucesos interiores como los exteriores aparezcan según ritmo y compás iguales o proporcionales" (García Bacca, 1947: 34).

Por último, Bacca destaca todavía otro tipo de reloj, al cual le corresponde otro tipo de pensamiento filosófico paralelo. Se trata del "reloj atómico", y será Bergon quien mejor refleje su funcionamiento en el plano filosófico. Dicho reloj atómico consistirá en un cuerpo radiactivo del cual emanarán, de forma discontinua e indistinta, partículas alfa o partículas beta o electrones libres o rayos gamma... Será, pues, un reloj espontáneo, saltarín e imprevisible que no estará regido por leyes mecanicistas y deterministas. Fluirá discontinuo y sus segundos serán desiguales, a diferencia de los movimientos uniformes e idénticos de las manecillas de los relojes ordinarios. Este reloj atómico desintegrará el ideal físico-matemático de un tiempo continuo y perfectamente uniforme; y ciertamente será el tiempo creador de Bergson, vital y novedoso, quien mejor lo caracterice. Y ello porque Bergson no admitirá, contra la metafísica y la física clásica y tradicional, la idea de una realidad consistente en un armario de posibles o preexistentes que no dejen margen alguno de originalidad ni a la realidad ni a los seres humanos: "...hay cosas que sólo llegan a ser posibles, una vez que efectivamente han pasado, y repugna que sean posibles antes de que hayan sido o estén siendo reales... si hablamos de verdad y no de mentirijillas, ser libre encierra esencialmente un elemento de originalidad, de imprevisibilidad, de creación... La vida es esencialmente libre. Y no consiste la libertad en elegir una de las posibilidades, sino en crear la posibilidad misma, en inventar" (García Bacca, 1947: 40-43). 


\section{Referencias}

Améry, Jean. (1968). Revuelta y Resignación. Acerca del envejecer. Valencia: Pre-Textos, 2001.

Bachelard, Gastón. (1932). La intuición del instante. Buenos Aires: Ediciones Siglo Veinte, 1973.

Bergson, Henri. (1957). Memoria y vida. Barcelona: Altaya, 1998.

Borges, Jorge Luís. (1979). Borges oral. Madrid: Alianza, 1998.

Browne, Thomas. (2005). El arte de la digresión. Madrid: Siruela.

Carroll, Lewis. (1865). Alicia en el país de las maravillas. Madrid: Plaza \& Jenés, 1999.

Cioran, Emile. (1973). Del inconveniente de haber nacido. Madrid: Taurus, 1998.

Conill, Jesús. (1981). El tiempo en la filosofía de Aristóteles. Valencia: Series Valentina X, 1981.

Eliade, Mircea. (1949). El mito del eterno retorno. Madrid-Buenos Aires: Alianza-Emecé, 1982.

Eliade, Mircea. (1958). Diario portugués. Barcelona: Kairós, 2001.

Eliade, Mircea. (1979). La prueba del laberinto. Madrid: Ediciones Cristiandad, 1980.

Eliade, Mircea. (1982). Diecinueve rosas. Barcelona: Kairós, 1999.

Elias, Norbert. (1989). Sobre el tiempo. Madrid: FCE.

García Bacca, Juan David. (1947). Nueve grandes filósofos contemporáneos y sus temas. Barcelona: Anthropos, 1990.

Gould, Stephen Jay. (1987). La flecha del tiempo. Mitos y metáforas en el descubrimiento del tiempo geológico. Madrid: Alianza Universidad, 1992.

Heidegger, Martin. (1995). El concepto del tiempo. Madrid: Mínima Trotta, 2001.

Larre, Claude. (1979). Percepción empírica del tiempo y concepción de la historia en el pensamiento chino. En Paul Ricoeur. Las culturas y el tiempo (pp. 33-67). Salamanca/Paris: Sígueme/UNESCO.

Lizcano, Emmanuel. (1992). El tiempo en el imaginario social chino. Archipiélago, 10-11, 59-61

Norbert, Elias. (1984). Sobre el tiempo. Madrid: F.C.E., 1989.

Panikkar, Raimundo. (1979). Tiempo e historia en la tradición de la India. En Paul Ricoeur. Las culturas y el tiempo (pp. 68-88). Salamanca/Paris: Sígueme/UNESCO.

Panofsky, Erwin. (1972). Estudios sobre iconología. Madrid: Alianza Editorial, 1985.

Ricoeur, Paul. (1979a). El tiempo y las filosofías. Salamanca: Ediciones Sígueme.

Ricoeur, Paul. (1979b). Las culturas y el tiempo. Salamanca: Salamanca/Paris: Sígueme/UNESCO.

San Agustín (1997). Confesiones. Barcelona: Altaya.

Shakespeare, William. (1623). Macbeth. Barcelona: Planeta, 2000. 
Unamuno, Miguel. (1913). Del sentimiento trágico de la vida. Barcelona: Circulo de Lectores, 1998.

Whitrow, Gerald James. (1988). El tiempo en la historia. Barcelona: Crítica, 1990.

\section{Historia editorial}

Recibido: 26/12/2004

Primera revisión: 11/11/2005

Aceptado: 15/11/2005

\section{Formato de citación}

Navarro, Eduardo Vicente. (2006). El Tiempo a través del tiempo. Athenea Digital, 9, 1-18. Disponible en http://antalya.uab.es/athenea/num9/navarro.pdf

Eduardo Vicente Navarro. (Valencia, 1975). Licenciado en Filosofía por la Universitat de València (2001). Diploma de Estudios Avanzados [DEA] (2004).

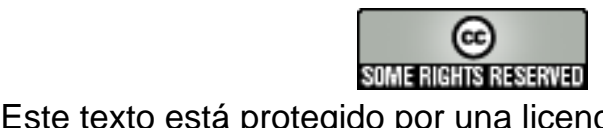

Este texto está protegido por una licencia $\underline{\text { Creative Commons }}$

Usted es libre de copiar, distribuir y comunicar públicamente la obra bajo las siguientes condiciones:

Reconocimiento: Debe reconocer y citar al autor original.

No comercial. No puede utilizar esta obra para fines comerciales.

Sin obras derivadas. No se puede alterar, transformar, o generar una obra derivada a partir de esta obra.

\section{$\underline{\text { Resumen de licencia }}$}

$\underline{\text { Texto completo de la licencia }}$ 